\title{
A MEDIUM FOR THE RAPID RECOGNITION OF PENICILLIN-RESISTANT COAGULASE-POSITIVE STAPHYLOCOCCI
}

\author{
BY \\ RUTH KLEMPERER AND GEOFFREY HAUGHTON \\ From the Pathological Laboratory, Royal South Hants Hospital, Southampton, and \\ the Department of Physiology, Southampton University.
}

(RECEIVED FOR PUBLICATION JUNE 7, 1956)

Because of the growing importance of staphylococcal cross-infection in hospitals, a simple, reliable, and rapid method for the primary isolation of these organisms from wounds, carriers, clothing, bedding, and dust is needed. That most widely used is growth on plain or blood agar plates, from which suspect colonies are picked and tested by either the tube or slide coagulase test. The addition of salt to nutrient agar to a final concentration of $7 \%$ suppresses the growth of other bacteria, and is of great value in recovering staphylococci from faeces, but it has the disadvantage that colonies may not appear for 48 hours, and do not always give a positive slide coagulase test unless subcultured on nutrient agar. A great improvement is the use of nutrient agar containing phenolphthalein phosphate as employed by Barber and Burston (1955) in their studies of hospital infections. After incubation the plates were exposed to ammonia vapour, when phosphatase-producing colonies, mainly coagulase-positive staphylococci, gave a reddish colour, and were later tested for coagulase production by the tube test.

Duthie and Lorenz (1952) added sterile human fibrinogen with a little human plasma to molten agar at $50^{\circ} \mathrm{C}$, , after which plates were rapidly poured. Such plates gave opaque rings of fibrin around coagulase-positive colonies, and were used for selecting good coagulase producers. Boake (1956) for similar purposes used $2 \%$ bovine fibrinogen sterilized by Seitz filtration which was added to an equal volume of agar together with human serum. In a recent study of cross-infection in a hospital, plates containing either human or bovine fibrinogen were of immense value for the detection of the responsible strain before phage typing. At first some difficulty was met in securing consistent batches of plates and their composition was therefore studied in detail. This was especially important in the case of bovine fibrinogen which had to be filtered, since only a fraction of the fibrinogen came through in the filtrate. Since the strain sought was penicillin resistant an improved selection was obtained by the addition of a small amount of penicillin to each plate. Fibrinogen plates are not widely used for this work, possibly because it is not realized that they are readily prepared from commercially available fibrinogen, and it is hoped that the results now presented will encourage their use in a field in which they have for too long been neglected.

\section{Materials and Methods}

Fibrinogen.-A minimum of $50 \mathrm{mg}$. of any sterile fibrinogen with 2 to $3 \mathrm{ml}$. of any fresh, sterile human plasma for each $100 \mathrm{ml}$. of nutrient agar was essential. At first sterile human fibrinogen, ether-precipitated from time-expired human plasma (Kekwick and Mackay, 1954), was made available through the kindness of the Blood Products Laboratory, Lister Institute. Elstree, Herts, and gave excellent results. Since the amount needed over a period was relatively high. it was decided to use commercially available bovine fibrinogen (Fraction I), approximately $40^{\circ} \%$ clottable protein, supplied by Messrs. Armour, Hampden Park. Eastbourne, Sussex, and several methods for sterilizing this were tested as follows.

(a) Seitz Filtration.-Because of the high absorp- $\mathbb{N}$ tion on Seitz filter pads it was essential to use the $N_{\tilde{\omega}}$ most concentrated solution possible with the smallest pad permitting filtration. In general, the following procedure was adequate, but this can be modified according to the equipment available. Twenty millilitres of $3 \%$ Armour's bovine fibrinogen preparation in saline was clarified by filtering through a Whatman No. 1 paper. Ten $\mu$ g. of soya bean trypsin inhibitor was added and the solution filtered through a $4 \mathrm{~cm}$. Seitz filter pad moistened previously with $3.8 \%$ sodium citrate. A biuret test on the filtrate should show at least a $1 \%$ solution of protein, and $5 \mathrm{ml}$. of the filtrate with 2 to $3 \mathrm{ml}$. of sterile human plasma was 


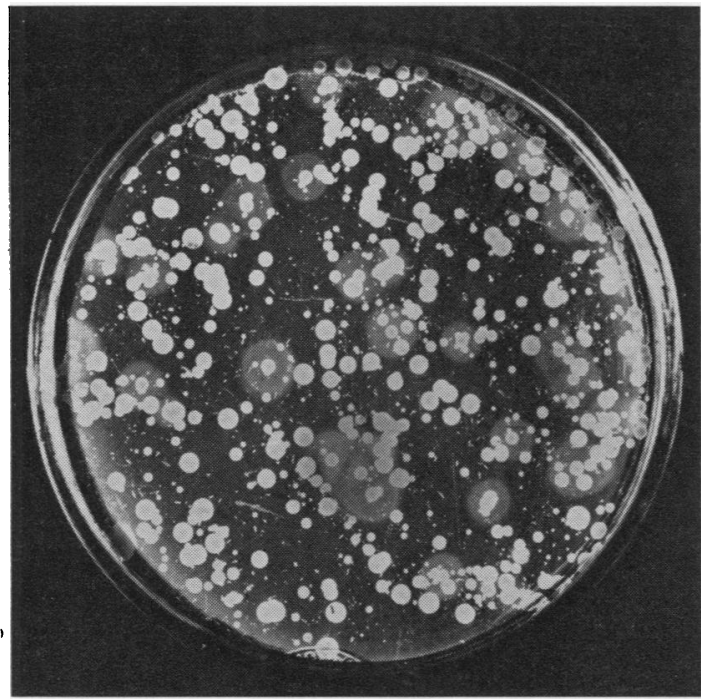

FIG. 1.-Dust sample spread on fibrinogen agar. Coagulase-positive colonies show marked haloes.

then added to $100 \mathrm{ml}$. of molten agar at $50^{\circ} \mathrm{C}$., mixed, and poured immediately. Filtered bovine fibrinogen clots spontaneously after a few hours so that plates should be poured soon after filtering. About $10 \mathrm{ml}$. of medium was adequate for five-inch plates and these showed no deterioration when stored for several weeks at $4^{\circ} \mathrm{C}$.

(b) Membrane Filtration.-Using "oxoid" $4 \mathrm{~cm}$. membranes made by Messrs. Oxo, Ltd., Thames House, London, E.C.4, it was found possible to filter between 5 and $10 \mathrm{ml}$. of the above $3 \%$ solution in saline before blocking. This was then regarded as being about $1.5 \%$ bovine fibrinogen.

(c) Irradiation.-Batches of bovine fibrinogen were irradiated with neutrons at the Atomic Energy Research Establishment, Harwell, England. The minimal dose giving complete sterility was $2 \times 10^{6} \mathrm{r}$ which produced about 30 to $50 \%$ loss in the clotting activity of the fibrinogen. This is undoubtedly the method of choice, but is likely to be costly unless large batches. 15-17 g., of fibrinogen are needed. Fibrinogen sterilized by irradiation remained stable when stored below $0^{\circ} \mathrm{C}$.

Plasma Plates.-Fresh human plasma to a final concentration of $15 \%$ was added to agar at $50^{\circ} \mathrm{C}$. and the plates poured immediately.

Tube Coagulase Test.-The method of Fisk (1940) was used. A small quantity, $0.1 \mathrm{ml}$., of an overnight broth culture of the bacteria was added to $1 \mathrm{ml}$. of $10 \%$ sterile human plasma in saline. The tubes were held at $37^{\circ} \mathrm{C}$. and examined for clots at four and 24 hours.

Penicillin.-Since practically all strains responsible for hospital cross-infection are good penicillinase

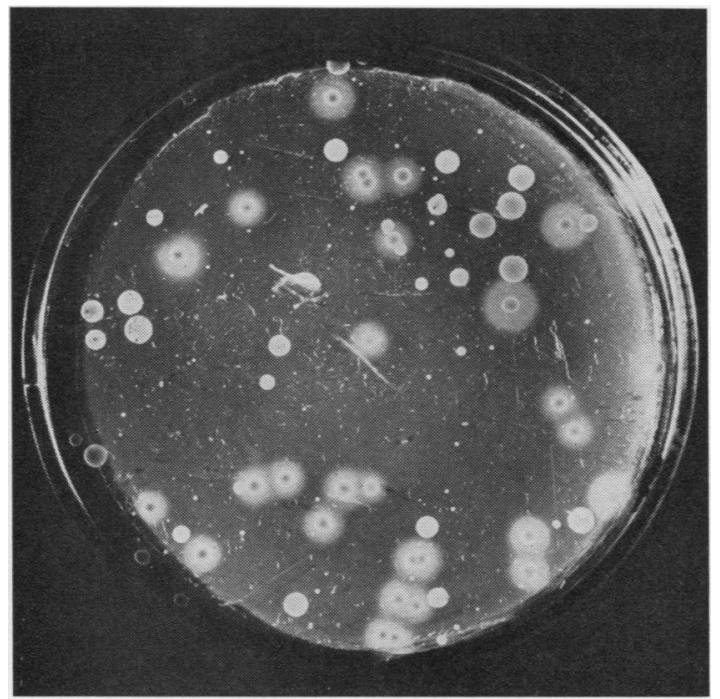

FIG. 2.-Same dust sample as Fig. 1 grown on penicillin agar containing $0 \cdot 1 \mathrm{u}$. penicillin per $\mathrm{ml}$. to suppress penicillin-sensitive bacteria.

producers, penicillin to a final concentration of 0.1 $\mathrm{u} . / \mathrm{ml}$. of agar was added to those plates used for the examination of dust and blankets.

\section{Results}

The ease with which coagulase-positive staphylococcal colonies may be recognized in dust samples plated on fibrinogen plates is evident in Fig. 1. If the staphyloccoci sought are penicillinase producers, then their recognition and enumeration is even simpler when penicillin has been added as in Fig. 2, which shows a plate spread with an equal quantity of the dust sample used in Fig. 1. The dust in question was collected from a vacuum cleaner, shaken in broth, and samples of the latter spread on each plate.

Certain points should be remembered in using these plates. The full opacity does not develop around the colonies during incubation, but deepens if the plates are subsequently cooled in a refrigerator before examination. The addition of soya bean trypsin inhibitor serves a double purpose. First, samples of bovine or human fibrinogen in solution are sometimes unstable due to the presence of active plasmin. In addition plasminogen may be activated during Seitz filtration. Plates containing active plasmin may show poor or no fibrin haloes, since either fibrinogen or fibrin is readily damaged. Secondly, many strains of staphylococci produce staphylokinase, which activates plasminogen (Lack, 1948). Soya bean inhibitor, though not essential, readily inhibits 
plasmin in the concentration used, and it is therefore worth while adding it to the medium if this is possible. If it is not available it is advisable to spot a known coagulase-producing strain on one section of the medium as a check for the reliability of the plates. A solution of $1 \mathrm{mg}$. $/ \mathrm{ml}$. of the inhibitor in $\mathrm{N} / 20 \mathrm{HCl}$ is stable for months at $4^{\circ} \mathrm{C}$. and the addition of 5 drops to each $20 \mathrm{ml}$. of fibrinogen before filtration is a simple matter.

The opacity round the colonies is due to free coagulase diffusing into the agar and causing clotting of the fibrinogen, so that positive colonies should give a positive coagulase tube test by any of the methods used. Since clumping in the slide test is a different reaction, depending on bound coagulase in the cell wall (Duthie, 1954), not all colonies giving haloes on fibrinogen plates will give positive slide tests, though the majority of strains, and specially those from pathological sources, will give both. This was borne out by testing 70 strains from various sources examined by $(a)$ subculturing on bovine fibrinogen plates, $(b)$ the tube test as used by Fisk (1940), and (c) the slide test in which colonies were emulsified in human plasma and examined for clumping.

\section{TABLE I}

RESULTS OF COAGULASE TESTS ON 70 STAPHYLOCOCCAL STRAINS BY THREE METHODS

\begin{tabular}{c|ccc}
\hline $\begin{array}{c}\text { No. of } \\
\text { Strains }\end{array}$ & $\begin{array}{c}\text { Fibrinogen } \\
\text { Plate Test }\end{array}$ & $\begin{array}{c}\text { Tube } \\
\text { Test }\end{array}$ & $\begin{array}{c}\text { Slide } \\
\text { Test }\end{array}$ \\
\hline 58 & ++ & - & - \\
3 & +- & - & Doubtful \\
1 & \pm & & - \\
\hline 8 & - & Nouderate. & Wedk.
\end{tabular}

In Table I it can be seen that the results of the plate and tube test were in full agreement. If anything the plate test was the easier to read, since the haloes were strong and stable. Only four of the 70 strains gave strong plate and tube tests with negative or doubtful slide tests, and these strains were almost certainly of reduced or doubtful virulencé. All strains recovered from infections gave all three reactions.

Other workers (Penfold, 1944; Reid and Jackson, 1945 ; Williams and Harper, 1946 ; Lack and Wailling, 1954) used plasma agar plates for the detection of coagulase-positive staphylococci. Colonies were recognizable as with fibrinogen plates except that the zone of opacity was less marked. Williams and Harper (1946) found that most batches made from $15 \%$ human plasma in agar were unreliable, and in addition they found that on poor plates a few coagulase-negative $\overrightarrow{\vec{S}}$ colonies gave haloes. A number of strains were examined on such plates in the present study, and six of these strains are shown in Fig. 3. The left-

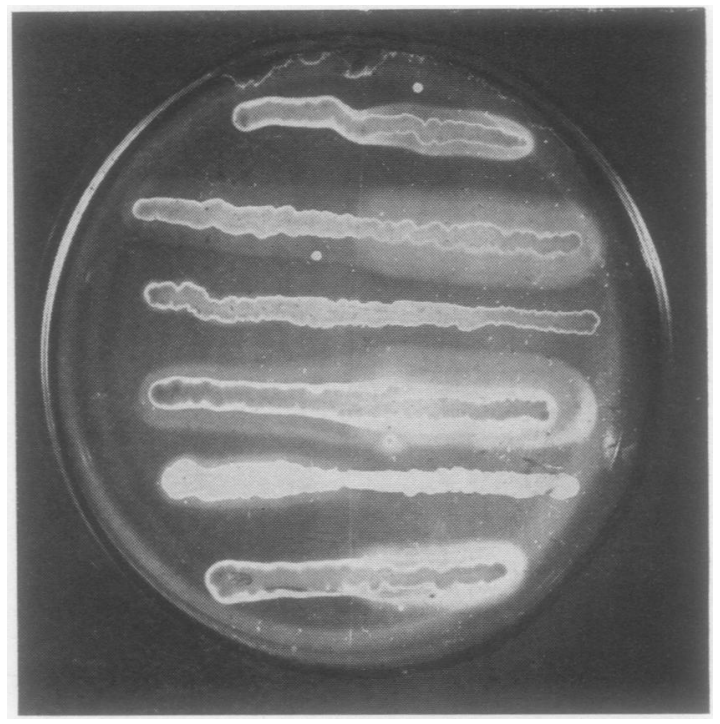

FIG. 3.-Comparison of six staphylococcalstrains grown on fibrinogen agar (right side) and plasma agar (left side). Strains referred to as 1 to 6 from top to bottom.

hand side of the plate was poured with plasma agar and the right-hand side with fibrinogen agar as used in Figs. 1 and 2, to illustrate the three main defects of the plasma plates. First, the opacity around the streaks, even with good coagulase- 8 producing strains such as 2 and 4 from the top. was difficult to see. Secondly, poor coagulaseproducing strains such as 1 and 6 from the top 8 gave no recognizable haloes in plasma-agar, $₹$ although their haloes were easily visible in fibrin- 9 ogen agar and they gave positive tube tests. Lastly, a strain such as 5 , which gave a negative tube test, had no halo on fibrinogen agar but showed a narrow zone of opacity on plasma agar. The o superiority of fibrinogen over plasma agar was $\tilde{O}$ therefore obvious.

\section{Summary}

Directions for making fibrinogen agar plates $\stackrel{\varnothing}{\varnothing}$ from any fibrinogen are given. Such plates readily detect coagulase-positive staphylococci in any site. and by the addition of penicillin are made more selective for penicillin-resistant strains.

We wish to thank Dr. E. S. Duthie for advice and encouragement, and Mr. D. Taplin for his photographic skill. We also wish to thank Dr. H. Bowen, 
of the Atomic Energy Research Establishment, Harwell, Berks, England, for irradiating trial batches of material.

\section{REFERENCES}

Barber, M., and Burston, J. (1955). Lancet, 2, 578. and Kuper, S. W. A. (1951). J. Path. Bact., 63, 65. Boake, W. C. (1956). I. Immunol., 76, 89.

Duthie, E. S. (1954). J. gen. Microbiol., 10, 427. — and Lorenz, L. L. (1952). Ibid., 6, 95.
Fisk, A. (1940). Brit. J. exp. Path., 21, 311.

Kekwick, R. A., and Mackay, M. E. (1954). Spec. Rep. Ser. med. Res. Coun. (Lond.), No. 286.

Lack, C. H. (1948). Nature (Lond.), 161, 559.

- and Wailling, D. G. (1954). J. Path. Bact., 68, 431.

Penfold, J. B. (1944). Ibid., 56, 247.

Reid, J. D., and Jackson, R. M. (1945). J. Lab. clin. Med., 30, 155.

Williams, R. E. O., and Harper, G. J. (1946). Brit. J. exp. Path., 27, 72. 